\title{
Inpatients’ Outcomes Following Diabetic Myocardial Infarction: Income, Insurance, and Length of Stay in Teaching vs. Nonteaching Hospitals in the United States
}

\author{
Priscilla O Okunji ${ }^{1 *}$, Johnnie Daniel ${ }^{2}$ and Anthony Wutoh ${ }^{3}$ \\ ${ }^{1}$ Howard University College of Nursing and Allied Health Sciences, Washington, DC, USA \\ ${ }^{2}$ Department of Sociology and Anthropology, Washington, DC, USA
}

${ }^{3}$ College of Pharmacy, Washington, DC, USA

\begin{abstract}
This paper assesses whether there is a significant difference in socioeconomic condition (income), insurance status, and Length of Stay (LOS) of inpatients diagnosed with diabetic myocardial infarction in teaching vs nonteaching hospitals. A retrospective data analysis of discharges was conducted from the 2008 Healthcare Cost and Utilization Project, Nationwide Inpatient Sample. Sample selection was based on the International Classification of Diseases, Ninth Revision, codes with LOS as the outcome variable. Teaching hospitals have longer LOS compared to nonteaching hospitals for patients with incomes below $\$ 48,000\left(x^{2}=16.185, \mathrm{df}=6, P \leq 0.013\right)$. The duration of hospital LOS is higher in teaching than in nonteaching hospitals for patient insurance $\left(X^{2}=24.975, \mathrm{df}=6, P=0.0001\right)$. For patients with Medicare, the hospital stay of 1 day and less is lower in nonteaching hospitals. Teaching hospitals have higher rates of LOS than nonteaching hospitals for the age group, 65-74 ( $\left.X^{2}=37.294, \mathrm{df}=6, P=0.0001\right)$. Especially for hospital stays of more than 6 days, the LOS is higher in teaching hospitals. The difference in LOS in teaching and nonteaching hospitals is statistically significant for males $(P=0.009)$ vs. females $(P=0.003)$. The results of this study indicate that the difference in LOS between teaching and nonteaching hospitals based on patient age, income, and insurance is statistically significant. When one controls for the independent variables in this study, the difference presented is large enough to affect clinical policy. These findings highlight the need for interventions to increase awareness of health care disparities that exist among inpatients with diabetic myocardial infarction, especially for low-income and older patients who do not qualify for Medicare.
\end{abstract}

Keywords: Teaching hospitals; Nonteaching hospitals; Myocardial infarction; Diabetes; Outcomes

\section{Background}

Coronary artery disease is the leading cause of premature, permanent disability in the United States, accounting for about $20 \%$ of disability allowances by the Social Security Administration (AHA) [1]. According to the 2008 National Healthcare Disparity Report, mortality from myocardial infarction (MI) in 2005 was 652,091, ranking first while diabetes ranked sixth with a mortality rate of 75,119 and total cost of $\$ 174$ billion with $\$ 116$ billion in direct medical cost. The total cost for cardiovascular diseases in 2008 was $\$ 448.5$ billion with a direct medical cost of $\$ 296.4$ billion [2]. Approximately $\$ 86$ billion, or $12 \%$, of all US health care expenditures can be attributed to diabetes. Hospital characteristics have important effects on hospital outcomes [3]. Most, but not all, prior studies have reported lower risk-adjusted mortality in teaching hospitals as compared with nonteaching hospitals [4], perhaps because the quality and processes of care delivered in teaching hospitals are better than those in nonteaching hospitals. However, few studies have reported more mortality rates in teaching hospitals and the outcomes in minor teaching hospitals. Hence, Polanczyk et al. [5] and Dowell et al. [6] concluded that whether the outcomes observed in minor teaching hospitals were due to hospital characteristics, quality, or process of care factors still needs to undergo further investigation.

Furthermore, most studies on the hospital characteristics and their treatment outcomes have been focused on other acute and chronic diseases like AIDS [7], chronic heart failure and pneumonia [8], acute MI alone [4], and cardiovascular diseases alone [5]. Other studies concentrate on hospital characteristics and patient safety indicators [9], preventable adverse effects [10] and effects of hospital characteristics and economy on T2D [6]. No study has focused on hospital characteristics and patients with both MI and T2D treatments with regard to patients' Length of Stay (LOS). Cook et al. [11], Dowell et al. [6], and Okunji [12] saw this need and recommended further investigation of these variables in teaching and nonteaching hospitals in the treatment of patients with T2D. Hence, the difference in teaching and nonteaching hospitals with respect to patients' LOS in MI inpatient with T2D was important for this particular population. For example, could teaching vs. nonteaching hospitals differ significantly in inpatients' LOS?

\section{Hypothesis: Specific Aims and Hypotheses}

\section{Specific aim 1}

To determine if there was a significant difference in outcome (LOS) for diabetic MI inpatients treated at teaching vs. non-teaching hospitals.

\section{Research hypothesis 1}

There was a significant difference in outcome (LOS) for diabetic MI inpatients admitted to teaching vs. nonteaching hospitals.

\section{Specific aim 2}

To determine if there was a significant difference in LOS by diabetic MI characteristics (age, gender, ethnicity, income, comorbidities, and insurance) in teaching vs. nonteaching hospitals.

${ }^{*}$ Corresponding author: Priscilla O Okunji, Howard University College of Nursing and Allied Health Sciences, Washington, DC, USA, E-mail: pokunji@aol.com

Received July 04, 2013; Accepted August 25, 2013; Published August 30, 2013

Citation: Okunji PO, Daniel J, Wutoh A (2013) Inpatients' Outcomes Following Diabetic Myocardial Infarction: Income, Insurance, and Length of Stay in Teaching vs. Nonteaching Hospitals in the United States. J Metabolic Synd 2: 125. doi:10.4172/2167-0943.1000125

Copyright: $\odot 2013$ Okunji PO, et al. This is an open-access article distributed under the terms of the Creative Commons Attribution License, which permits unrestricted use, distribution, and reproduction in any medium, provided the original author and source are credited. 
Citation: Okunji PO, Daniel J, Wutoh A (2013) Inpatients' Outcomes Following Diabetic Myocardial Infarction: Income, Insurance, and Length of Stay in Teaching vs. Nonteaching Hospitals in the United States. J Metabolic Synd 2: 125. doi:10.4172/2167-0943.1000125

\section{Research hypothesis 2}

There was a significant difference in LOS by patient characteristics (age, gender, ethnicity, income, comorbidities, and insurance) for diabetic MI inpatients in teaching vs. nonteaching hospitals.

\section{Theoretical Framework}

The organizing framework of this study was based on the Quality of Health Model of Care. This model proposed by the American Academy of Nursing Expert Panel on Quality Health Care (1998) is useful for measuring reciprocal directions of influences of multiple variables that affect quality of care and desired health outcomes. This dynamic model applied to evaluating health care delivery systems allows researchers to utilize data bases to delineate the relevant interrelationships between patient level characteristics, the context in which care is provided, the quality of provider intervention, and, ultimately, health outcomes. This model is an expansion of the framework proposed by Donabedian [13], which posits that structure affects process and process affects outcome when patient characteristics are considered as mediating outcomes. The Quality of Health Model broadens Donebenian's framework for quality improvement and outcomes management by examining dynamic relationships with indicators that not only act on but also reciprocally affect the various components. The current study may contribute to policy decision making for organizational or system-level improvements, development of interventions and training for improved provider clinical interventions or treatment options, and descriptively address patient-level needs for self-management.

\section{Research Design and Methodology}

The study design was a secondary data analysis from the 2008 Healthcare Cost and Utilization Project (HCUP) Nationwide Inpatient Sample (NIS) [14]. HCUP is a family of health care databases and related software tools and products developed through a federal-stateindustry partnership and are sponsored by the Agency for Healthcare Research and Quality (AHRQ). HCUP databases bring together the data collection efforts of state data organizations, hospital associations, private data organizations, and the federal government to create a national information resource of patient-level health care data (HCUP Partners). HCUP is the largest collection of longitudinal hospital care data in the United States and includes all-payer, encounter-level information beginning in 1988. These databases enable research on a broad range of health policy issues, including cost and quality of health services, medical practice patterns, access to health care programs, and outcomes of treatments at the national, state, and local market levels. Howard University Internal Review Board (IRB) clearance was obtained prior to the initiation of the project, along with the HIPAA certification by HCUP prior to database purchase.

\section{Patient measures}

Age (20 years and above); gender (male, female); ethnicity (white, black, Hispanic, Asian, Native American); income (\$1-38,999; \$39,000$\$ 47,999 ; \$ 48,000-\$ 62,999 ; \$ 63,000$ and above); insurance (Medicare, Medicaid, private including HMO, self-pay, no charge).

\section{Outcomes measures}

\section{LOS.}

\section{Study population}

The HCUP NIS [14] database contains data from 5 to 8 million hospital stays from 1000 hospitals sampled to approximately a $20 \%$ stratified sample of US community hospitals. In this research, participants' data were selected from the hospital discharge information according to patients' characteristics (age, gender, ethnicity, income, and insurance). Selection of samples was aided by the existing NIS database and ICD-9-CM (HCUP CCS) [15]. Patients aged up to 7 years were not included in this study based on the prevalence within this population of type 1 diabetes. However, among the age group 20 and above, young adults were included in this study because of the increased prevalence of type 2 diabetes in this population due to diet, lifestyle, and obesity. The NIS database samples were selected and extracted based on the following criteria: (a) inpatient diagnosed with both MI and T2D, (b) admitted in nonfederal hospitals, and (c) age 20 years and above; exclusions included (d) obstetrics-gynecologic, ear-nosethroat, orthopedic, and pediatric patients, and (e) short-term acute rehabilitation and long-term nonacute care patients, and psychiatric and alcoholism/chemical dependency treatment patients. In reviewing the statistical results of the study, we first indicated whether a finding was statistically significant. We then assessed the practical significance of the findings and indicated whether the observed differences were large enough to affect clinical policy.

\section{Results}

Nonteaching hospitals serve higher proportion of whites than do teaching hospitals Also, these patients may be transferred or die before discharge from teaching hospitals; hence other ethnic groups stay for a shorter period than the white population, with the biggest inequality among low-income patients and shorter LOS in nonteaching hospitals (Table 1).

A patient under 65 years of age was higher for teaching hospitals than for nonteaching hospitals; on the other hand the percentage of patients 75 years or older was higher for nonteaching hospitals than for teaching hospitals. The findings as it relates to Hypothesis 1 showed that teaching hospitals have longer LOS than nonteaching hospitals. Especially for a hospital stay of more than 4 days with exception of 2 days of LOS, the percentage of older patients is higher in nonteaching

\begin{tabular}{|c|c|c|}
\hline & Nonteaching Hospital & Teaching Hospital \\
\hline \multicolumn{3}{|l|}{ Age } \\
\hline Less than 45 years & 6.4 & 8.1 \\
\hline 45 to 54 & 15.6 & 17.3 \\
\hline 55 to 64 & 23.4 & 26.2 \\
\hline 65 to 74 & 24.1 & 23.9 \\
\hline 75 or older & 30.5 & 24.5 \\
\hline Number of cases & 2434 & 2008 \\
\hline \multicolumn{3}{|c|}{$\mathrm{x}^{2}=24, \mathrm{df}=4, P=.000$} \\
\hline \multicolumn{3}{|l|}{ Gender } \\
\hline Male & 56.7 & 60.3 \\
\hline Female & 43.3 & 39.7 \\
\hline Number of cases & 2435 & 2008 \\
\hline \multicolumn{3}{|l|}{$X^{2}=6, d f=1, P=.009$} \\
\hline \multicolumn{3}{|l|}{ Ethnicity } \\
\hline White & 75.5 & 67.5 \\
\hline Black & 6.6 & 14.0 \\
\hline Hispanic & 8.9 & 9.9 \\
\hline Other & 9.0 & 8.6 \\
\hline Number of cases & 2010 & 1609 \\
\hline$X^{2}=58, d f=3, P=.0001$ & & \\
\hline
\end{tabular}

Table 1: Percentage Distribution of Age, Gender, and Ethnicity of Diabetic Myocardial Infarction Patients in Nonteaching and Teaching Hospitals. 
Citation: Okunji PO, Daniel J, Wutoh A (2013) Inpatients' Outcomes Following Diabetic Myocardial Infarction: Income, Insurance, and Length of Stay in Teaching vs. Nonteaching Hospitals in the United States. J Metabolic Synd 2: 125. doi:10.4172/2167-0943.1000125

Page 3 of 6

hospitals. The difference in teaching and nonteaching hospitals is statistically significant because more older patients aged 65-74 years stayed longer in the hospital than their younger counterparts $\left(\chi^{2=37.294}\right.$, $\mathrm{df}=6, P=0.0001)($ Table 2$)$.

The percentage of males in both teaching $(60.3 \%)$ and nonteaching (56.7\%) hospitals was higher than the percentage of females in these hospitals. More females stayed longer days in the hospital than their male counterparts $\left(\chi^{2}=19.621, \mathrm{df}=6, P=0.003\right)$ with increased length of stay of 7 to 13 days in teaching $(24.9 \%)$ compared to nonteaching (21.3\%) hospitals (Table 3). The difference between teaching and nonteaching hospitals is statistically significant; however, it is not large enough to affect clinical policy.

Furthermore, the results indicate that more patients with Medicare had shorter $\operatorname{LOS}\left(\chi^{2}=24.975, \mathrm{df}=6, P=0.0001\right)$ in nonteaching hospitals, but those with self-pay stayed the fewest days in both teaching and nonteaching hospitals although Medicare was the major insurance used by inpatients with MI and T2D in 2008 (Table 4).

The extent of hospital LOS for a day or less than 1 day was higher in nonteaching than in teaching hospitals for income below $\$ 48,000$. Especially for the income groups of $\$ 1-\$ 38,999$ and $\$ 39,000-\$ 47,999$ the percentage was higher in nonteaching hospitals for 1 day and less and 4 days, respectively. The difference between teaching and nonteaching hospitals was statistically significant for lower-income patients and was large enough to affect clinical policy. The results have shown that the patient's length of stay is proportional to the patient's income, which may be due to the type of insurance. Insurance type may not qualify the patient to stay longer, have quality treatment, recover, and be discharged home. The percentage of hospital length of stay for a day or less than 1 day was higher in nonteaching than in teaching hospitals for patients with insurance, especially with Medicare (Table 5).

The difference between teaching and nonteaching hospitals was statistically significant and large enough to affect clinical policy. This may be due to the aged population coupled with the fact that the government covers this insurance from age 65 years and above. Hence one policy option is that Medicaid should be expanded to cover more patients who may not be qualified for Medicare.

The hospital length of stay for a day or less than 1 day is higher in nonteaching than in teaching hospitals in terms of patients' comorbidities. Especially for patients with hypertension, the rate is higher in nonteaching hospitals (Table 6). The percentage of longer lengths of stay (7-13 days) for congestive heart failure was also higher in nonteaching hospitals. The results correlate with the symptomatic effects of MI-high blood pressure resulting in rupture, clot, and necrotic tissues-which limit blood circulation and result in myocardial infarction. Thus, there should be a policy in place to screen all diabetic patients for hypertension and other co-morbidities to prevent complications such as MI.

\begin{tabular}{|c|c|c|c|c|c|c|c|c|c|c|}
\hline & \multicolumn{10}{|c|}{ Age } \\
\hline & \multicolumn{2}{|c|}{ Less than 45 years } & \multicolumn{2}{|c|}{45 to 54 years } & \multicolumn{2}{|c|}{55 to 64 years } & \multicolumn{2}{|c|}{65 to 74 years } & \multicolumn{2}{|c|}{75 years or older } \\
\hline & $\begin{array}{c}\text { Nonteaching } \\
\text { Hospital }\end{array}$ & $\begin{array}{l}\text { Teaching } \\
\text { Hospital }\end{array}$ & $\begin{array}{c}\text { Nonteaching } \\
\text { Hospital }\end{array}$ & $\begin{array}{l}\text { Teaching } \\
\text { Hospital }\end{array}$ & $\begin{array}{c}\text { Nonteaching } \\
\text { Hospital }\end{array}$ & $\begin{array}{l}\text { Teaching } \\
\text { Hospital }\end{array}$ & $\begin{array}{c}\text { Nonteaching } \\
\text { Hospital }\end{array}$ & $\begin{array}{l}\text { Teaching } \\
\text { Hospital }\end{array}$ & $\begin{array}{c}\text { Nonteaching } \\
\text { Hospital }\end{array}$ & $\begin{array}{l}\text { Teaching } \\
\text { Hospital }\end{array}$ \\
\hline \multicolumn{11}{|c|}{ Length of Stay } \\
\hline $\begin{array}{c}1 \text { day or less than } \\
1 \text { day }\end{array}$ & 9.0 & 4.9 & 9.8 & 8.6 & 9.0 & 7.2 & 11.1 & 6.5 & 12.4 & 8.9 \\
\hline 2 days & 16.0 & 21.0 & 18.7 & 21.0 & 14.6 & 16.3 & 12.8 & 12.9 & 11.3 & 11.6 \\
\hline 3 days & 21.2 & 21.0 & 20.3 & 19.5 & 19.7 & 20.5 & 20.3 & 14.0 & 15.7 & 15.7 \\
\hline 4 days & 19.2 & 19.8 & 14.2 & 13.2 & 14.2 & 12.5 & 15.5 & 10.6 & 13.6 & 12.0 \\
\hline 5 to 6 days & 17.3 & 13.0 & 12.9 & 14.1 & 16.9 & 17.5 & 16.7 & 17.5 & 15.2 & 18.3 \\
\hline 7 to 13 days & 14.7 & 16.0 & 19.3 & 18.1 & 19.5 & 19.8 & 18.1 & 27.5 & 24.0 & 22.6 \\
\hline 14 days or longer & 2.6 & 4.3 & 4.7 & 5.5 & 6.2 & 6.1 & 5.6 & 11.0 & 7.8 & 11.0 \\
\hline Total & 100.0 & 100.0 & 100.0 & 100.0 & 100.0 & 100.0 & 100.0 & 100.0 & 100.0 & 100.0 \\
\hline \multirow[t]{2}{*}{ Number } & 156 & 162 & 379 & 348 & 569 & 526 & 587 & 480 & 743 & 492 \\
\hline & \multicolumn{2}{|c|}{$\chi^{2}=4.729, \mathrm{df}=6, P=.579$} & \multicolumn{2}{|c|}{$X^{2}=1.401, \mathrm{df}=6, P=.966$} & \multicolumn{2}{|c|}{$X^{2}=2.318, d f=6, P=.888$} & \multicolumn{2}{|c|}{$\mathrm{X}^{2}=37.294, \mathrm{df}=6, P=.0001$} & \multicolumn{2}{|c|}{$X^{2}=9.025, d f=6, P=.172$} \\
\hline
\end{tabular}

Table 2:P Percentage Distribution of the Length of Stay by Age for Diabetic Myocardial Infarction Patients in Nonteaching and Teaching Hospitals.

\begin{tabular}{|c|c|c|c|c|}
\hline & \multicolumn{4}{|c|}{ Gender } \\
\hline & \multicolumn{2}{|c|}{ Male } & \multicolumn{2}{|c|}{ Female } \\
\hline & Nonteaching Hospital & Teaching Hospital & Nonteaching Hospital & Teaching Hospital \\
\hline \multicolumn{5}{|l|}{ Length of Stay } \\
\hline 1 day or less than 1 day & 10.6 & 7.4 & 10.6 & 7.8 \\
\hline 2 days & 14.1 & 18.1 & 13.6 & 11.7 \\
\hline 3 days & 20.3 & 19.2 & 16.8 & 15.3 \\
\hline 4 days & 14.3 & 12.6 & 15.2 & 12.7 \\
\hline 5 to 6 days & 15.6 & 16.5 & 15.8 & 17.0 \\
\hline 7 to 13 days & 19.3 & 19.6 & 21.3 & 24.9 \\
\hline 14 days or longer & 5.6 & 6.6 & 6.6 & 10.7 \\
\hline Total & 100.0 & 100.0 & 100.0 & 100.0 \\
\hline \multirow[t]{2}{*}{ Number } & 1381 & 1210 & 1054 & 798 \\
\hline & \multicolumn{2}{|c|}{$X^{2}=17.072$, df $=6, P=.009$} & \multicolumn{2}{|c|}{$X^{2}=19.621, d f=6, P=.003$} \\
\hline
\end{tabular}

Table 3: Percentage Distribution of the Length of Stay by Gender for Diabetic Myocardial Infarction Patients in Non- Teaching and Teaching Hospitals. 
Citation: Okunji PO, Daniel J, Wutoh A (2013) Inpatients' Outcomes Following Diabetic Myocardial Infarction: Income, Insurance, and Length of Stay in Teaching vs. Nonteaching Hospitals in the United States. J Metabolic Synd 2: 125. doi:10.4172/2167-0943.1000125

Page 4 of 6

\begin{tabular}{|c|c|c|c|c|c|c|c|c|}
\hline & \multicolumn{8}{|c|}{ Income } \\
\hline & \multicolumn{2}{|c|}{$\$ 1$ to $\$ 38,999$} & \multicolumn{2}{|c|}{$\$ 39,000-\$ 47,999$} & \multicolumn{2}{|c|}{$\$ 48,000-\$ 62,999$} & \multicolumn{2}{|c|}{$\$ 63,000$ or Higher } \\
\hline & $\begin{array}{l}\text { Nonteaching } \\
\text { Hospital }\end{array}$ & $\begin{array}{l}\text { Teaching } \\
\text { Hospital }\end{array}$ & $\begin{array}{l}\text { Nonteaching } \\
\text { Hospital }\end{array}$ & $\begin{array}{l}\text { Teaching } \\
\text { Hospital }\end{array}$ & $\begin{array}{c}\text { Nonteaching } \\
\text { Hospital }\end{array}$ & $\begin{array}{l}\text { Teaching } \\
\text { Hospital }\end{array}$ & $\begin{array}{c}\text { Nonteaching } \\
\text { Hospital }\end{array}$ & $\begin{array}{l}\text { Teaching } \\
\text { Hospital }\end{array}$ \\
\hline \multicolumn{9}{|l|}{ Length of Stay } \\
\hline $\begin{array}{l}1 \text { day or less } \\
\text { than } 1 \text { day }\end{array}$ & 12.1 & 6.2 & 9.6 & 9.2 & 9.2 & 7.1 & 11.6 & 8.4 \\
\hline 2 days & 12.3 & 14.1 & 13.7 & 17.6 & 16.4 & 14.7 & 13.4 & 15.8 \\
\hline 3 days & 20.1 & 18.3 & 17.7 & 18.6 & 18.2 & 18.4 & 19.0 & 14.4 \\
\hline 4 days & 15.2 & 13.4 & 16.4 & 9.9 & 13.2 & 11.3 & 13.9 & 16.0 \\
\hline 5 to 6 days & 15.9 & 14.6 & 15.8 & 16.9 & 16.4 & 18.4 & 14.2 & 17.5 \\
\hline 7 to 13 days & 17.7 & 23.9 & 21.6 & 20.4 & 20.8 & 21.7 & 21.0 & 19.6 \\
\hline 14 days or longer & 6.7 & 9.5 & 5.2 & 7.4 & 6.0 & 8.3 & 6.8 & 8.4 \\
\hline Total & 100.0 & 100.0 & 100.0 & 100.0 & 100.0 & 100.0 & 100.0 & 100.0 \\
\hline \multirow[t]{2}{*}{ Number } & 705 & 568 & 773 & 544 & 501 & 434 & 395 & 418 \\
\hline & \multicolumn{2}{|c|}{$X^{2}=23.032, \mathrm{df}=6, P=0.001$} & \multicolumn{2}{|c|}{$X^{2}=16.185, \mathrm{df}=6, P=0.013$} & \multicolumn{2}{|c|}{$X^{2}=4.660, d f=6, P=0.588$} & \multicolumn{2}{|c|}{$X^{2}=8.396, d f=6, P=0.211$} \\
\hline
\end{tabular}

Table 4: Percentage Distribution of the Length of Stay by Income for Diabetic Myocardial Infarction Patients in Nonteaching and Teaching Hospitals

\begin{tabular}{|c|c|c|c|c|c|c|c|c|c|c|}
\hline & \multicolumn{10}{|c|}{ Type of Health Insurance } \\
\hline & \multicolumn{2}{|c|}{ Medicare } & \multicolumn{2}{|c|}{ Medicaid } & \multicolumn{2}{|c|}{ Private } & \multicolumn{2}{|c|}{ Self-Pay } & \multicolumn{2}{|c|}{ Other } \\
\hline & $\begin{array}{c}\text { Nonteaching } \\
\text { Hospital }\end{array}$ & $\begin{array}{l}\text { Teaching } \\
\text { Hospital }\end{array}$ & $\begin{array}{c}\text { Nonteaching } \\
\text { Hospital }\end{array}$ & $\begin{array}{l}\text { Teaching } \\
\text { Hospital }\end{array}$ & $\begin{array}{c}\text { Nonteaching } \\
\text { Hospital }\end{array}$ & $\begin{array}{l}\text { Teaching } \\
\text { Hospital }\end{array}$ & $\begin{array}{c}\text { Nonteaching } \\
\text { Hospital }\end{array}$ & $\begin{array}{l}\text { Teaching } \\
\text { Hospital }\end{array}$ & $\begin{array}{c}\text { Nonteaching } \\
\text { Hospital }\end{array}$ & $\begin{array}{l}\text { Teaching } \\
\text { Hospital }\end{array}$ \\
\hline \multicolumn{11}{|l|}{ Length of Stay } \\
\hline $\begin{array}{c}1 \text { day or less than } \\
1 \text { day }\end{array}$ & 11.6 & 7.9 & 10.0 & 8.6 & 9.1 & 5.5 & 11.1 & 11.8 & 10.2 & 8.7 \\
\hline 2 days & 12.0 & 13.0 & 19.4 & 14.1 & 16.4 & 18.0 & 14.8 & 22.1 & 8.0 & 18.5 \\
\hline 3 days & 16.3 & 15.0 & 21.9 & 11.7 & 21.0 & 22.0 & 21.6 & 22.8 & 27.3 & 18.5 \\
\hline 4 days & 14.3 & 10.8 & 10.6 & 12.3 & 15.9 & 14.4 & 14.2 & 15.4 & 17.0 & 17.4 \\
\hline 5 to 6 days & 16.4 & 17.5 & 11.9 & 15.3 & 15.1 & 17.6 & 16.7 & 12.5 & 15.9 & 12.0 \\
\hline 7 to 13 days & 22.2 & 24.9 & 19.4 & 26.4 & 17.5 & 17.9 & 19.8 & 12.5 & 15.9 & 18.5 \\
\hline 14 days or longer & 7.2 & 10.9 & 6.9 & 11.7 & 5.0 & 4.6 & 1.9 & 2.9 & 5.7 & 6.5 \\
\hline Total & 100.0 & 100.0 & 100.0 & 100.0 & 100.0 & 100.0 & 100.0 & 100.0 & 100.0 & 100.0 \\
\hline \multirow[t]{2}{*}{ Number } & 1298 & 983 & 160 & 163 & 569 & 526 & 162 & 136 & 88 & 92 \\
\hline & \multicolumn{2}{|c|}{$\begin{array}{c}\mathrm{X}^{2}=24.975, \mathrm{df}=6, P= \\
0.0001\end{array}$} & \multicolumn{2}{|c|}{$\begin{array}{c}\mathrm{X}^{2}=11.173, \mathrm{df}=6, P= \\
0.083\end{array}$} & \multicolumn{2}{|c|}{$\mathrm{X}^{2}=8.384, \mathrm{df}=6, P=0.211$} & \multicolumn{2}{|c|}{$x^{2}=5.902, d f=6, P=0.434$} & \multicolumn{2}{|c|}{$X^{2}=6.108, d f=6, \quad P=0.411$} \\
\hline
\end{tabular}

Table 5: Percentage Distribution of the Length of Stay by Type of Health Insurance for Diabetic Myocardial Infarction Patients in Nonteaching and Teaching Hospitals.

\begin{tabular}{|c|c|c|c|c|c|c|}
\hline \multicolumn{7}{|c|}{ Comorbidities } \\
\hline & \multicolumn{2}{|c|}{ Congestive Heart Failure } & \multicolumn{2}{|c|}{ Chronic Pulmonary Disease } & \multicolumn{2}{|c|}{ Hypertension } \\
\hline & Nonteaching Hospital & Teaching Hospital & Nonteaching Hospital & Teaching Hospital & Nonteaching Hospital & Teaching Hospital \\
\hline \multicolumn{7}{|l|}{ Length of Stay } \\
\hline 1 day or less than 1 day & 5.3 & 9.4 & 8.1 & 8.3 & 10.9 & 6.9 \\
\hline 2 days & 7.1 & 4.2 & 13.9 & 10.2 & 13.7 & 15.2 \\
\hline 3 days & 11.8 & 10.4 & 16.9 & 15.2 & 18.6 & 18.5 \\
\hline 4 days & 11.8 & 14.6 & 12.1 & 11.2 & 14.8 & 12.4 \\
\hline 5 to 6 days & 13.6 & 12.5 & 14.4 & 17.5 & 15.5 & 16.7 \\
\hline 7 to 13 days & 34.9 & 25.0 & 27.5 & 26.7 & 19.9 & 21.5 \\
\hline 14 days or longer & 15.4 & 24.0 & 7.1 & 10.9 & 6.5 & 8.8 \\
\hline Total & 100.0 & 100.0 & 100.0 & 100.0 & 100.0 & 100.0 \\
\hline \multirow[t]{2}{*}{ Number } & 169 & 96 & 396 & 303 & 1681 & 1457 \\
\hline & \multicolumn{2}{|c|}{$\chi^{2}=7.231, \mathrm{df}=6, P=0.300$} & \multicolumn{2}{|c|}{$\mathrm{X}^{2}=6.269, \mathrm{df}=6, P=.394$} & \multicolumn{2}{|c|}{$X^{2}=25.236, \mathrm{df}=6, P=0.0001$} \\
\hline
\end{tabular}

Table 6: Percentage Distribution of the Length of Stay by Selected Comorbidities for Diabetic Myocardial Infarction Patients in Nonteaching and Teaching Hospitals.

\section{Discussion}

The outcomes of this study are in line with those of Hogan et al. [16], who reported that although MI and T2D disorders affect all age groups, the diseases become increasingly prevalent with age and have the greatest effect on elderly people, as well as minority ethnic populations. Hogan et al. [16] estimated that more than $18 \%$ of adults older than 65 have diabetes, the majority diagnosed with type 2 diabetes. As the fifth leading cause of death in the United States, this disease has a significant effect on health, quality of life, longevity, and health care systems [16]. 
The result supports the observation that women usually do not exhibit classical symptoms of MI like their male counterparts, and thus they are not aggressively treated. Their conditions are usually complicated by the time they are diagnosed with MI. According to Cook et al. [11], Silent Myocardial Ischemia (SMI), a common disorder, has been studied by different research groups for the past 25 years. It is known that SMI is more common in patients with T2D than in the general population, even though the factors that contribute to the health care disparity in treatments and outcomes are unclear. Despite the fact that the number of males who were admitted far outnumbered females, the fewer females who were admitted stayed longer in the hospital than did males [11].

Between teaching and nonteaching hospitals there was a significant difference in LOS by income lower than $\$ 48,000$, but this was not significant for patients with income higher than $\$ 48,000$. Within the income group $\$ 1-\$ 39,999$, the difference was significant for patients with LOS of a day or less than 1 day in nonteaching hospitals (12.1\%) than in teaching hospitals (6.2\%). Hence the effect of income did correlate with the notion that income is proportional to the length of stay. Generally, the lower a patient's income is, the shorter his/her length of stay. This correlation may be due to the type of insurance or income that may not qualify the patient to have quality treatment procedures and enable them to stay longer. This difference is also significant among all minority ethnic groups who stayed a day or less in nonteaching hospitals compared with teaching hospitals.

Each year in the United States, the numbers of people who are underinsured and uninsured rises. As the population of the United States becomes more diverse, minorities are more likely to be uninsured because of their lack of education and cultural barriers to health care. This analysis explains why the method of health care payment is crucial to the patients' outcome. The investigators suggest that commercial insurance companies tend to focus more on profit rather than on the outcome of the patients, which explains why patients who stayed the least were not necessarily the patients most fit to be discharged. Hence, the recent proposed healthcare reform would be efficacious if one could also count on quality and affordable care. If this new reform is adopted, Medicaid will be expanded to millions of people and will increase eligibility for Medicaid to lower-income individuals. It is expected that the federal government will initially bear the entire debt or taxation burden of this expansion, with states assuming some of the burden in later years [17].

Hence, these results support the alternative hypothesis that there is a significant difference in teaching and nonteaching hospitals and LOS when one controls for patient age, gender, ethnicity, income, and insurance possession for patients admitted with both MI and T2D to US hospitals in 2008.

This study has several limitations. First, it was based on a retrospective analysis of a nationwide hospital discharge database (HCUP NIS ) [14]. The variables that affected individual health status at admissions, such as duration and patterns of disease, knowledge of the disease state, adherence to therapeutic interventions, and previous lifestyle behaviors, were not included in the database [6]. Second, MI in this study includes both old MI and acute MI as classified in HCUPNIS ICD 9 codes (41000). It is well known that the pathophysiologies of the diseases associated to this code are quite different, and the different treatment strategies may influence LOS strongly. According to Steinberg et al. [18], although ICD-9 codes have been in use for decades to classify patients with AMI in the United States, they did not allow characterization of patients with ST Elevation MI (STEMI) vs. non-ST elevation myocardial infarction (NSTEMI).
Furthermore, many factors influence people's efforts to change behavior in a way that improves and maintains health status, and the factors are not provided in the database used. These factors include life style, level of education, self-esteem, motivation, and self-image. The value placed on health, the threat of potential losses, and the perceived benefits of behavior modifications are important motivating factors. The patient-support network and availability of health-promotion programs and health care systems have influence on health care behaviors. Some people may be prevented from accessing health-promotion programs because of medical insurance, as discussed in this study.

\section{Significance of Study}

Because of the challenges involved in analyzing from secondary data the attributes that contribute to quality care, this study not only gives the data about LOS of inpatients with both MI and T2D, but it also provides the most detailed and recent data now available to compare quality of care for this population between teaching and nonteaching hospitals. There were disparities noted in the LOS outcome, most significantly in the equity area reflecting differences in patient age, gender, ethnic group, income, and insurance possession.

First, there was a significant relationship between patients' insurance and gender among patients admitted with MI and T2D. The disparity between gender and patient insurance is troubling and in line with findings. Okunji [12] reported that possession of insurance is crucial in access to health care, and these findings indicated that more men of all ethnical groups consistently had Medicare insurance (all types) than their female counterparts $(P=0.0001)$.This result may explain why more males $1210(60.3 \%)$ were admitted in teaching hospitals and more females 1054 (43.3\%) were admitted in nonteaching hospitals. Older patients (65-74) had the shortest LOS. There was significant difference between the outcomes of teaching and nonteaching hospitals based on LOS. Ayanian et al. [8] reported that quality of care was consistently better in large teaching hospital than nonteaching hospitals; however, the authors confirmed the limitations of their study-documentation may have been more complete in teaching hospitals than in nonteaching hospitals because key information could be recorded by either attending or resident physicians.

\section{Future Research}

Further studies should be done to determine differences between teaching and nonteaching patient mortality rates using a more robust database that can account for all confounding variables in order to accurately predict the outcome. Results of further studies may warrant serious consideration in the formulation of national policies and programs to improve the quality of health care among inpatients with MI and T2D. Substantial overlap and inconsistency exists in ICD-9 codes for STEMI and NSTEMI patients, and the ICD-code 41000 is used for the two diseases. The new changes to future ICD-10 coding should allow a better description of quality measures and outcomes of the two different kinds of MI patients.

\section{Implications}

Acute care facilities in the United States spent $\$ 83$ billion in 2008 caring for people with diabetes. One of every 5 hospitalizations involved a person with diabetes during that year. This amounts to $23 \%$ of hospital expenditures to treat all conditions in 2008. According to HCUP NIS Agency AHRQ [14], the expenditures in these hospital included costs associated with more than 540,000 hospital stays.

Hence, there is an established association between hyperglycemia, length of stay, and hospital costs in T2D inpatients. These patients 
Citation: Okunji PO, Daniel J, Wutoh A (2013) Inpatients' Outcomes Following Diabetic Myocardial Infarction: Income, Insurance, and Length of Stay in Teaching vs. Nonteaching Hospitals in the United States. J Metabolic Synd 2: 125. doi:10.4172/2167-0943.1000125

are known to require longer lengths of hospitalization for any given admission diagnosis [12,19-22]. The increased LOS is probably related to the degree of hyperglycemia present during the course of hospitalization. Estrada et al. [23] found that the LOS among cardiac surgery patients with diabetes was 0.76 days longer for every $50-\mathrm{mg} /$ $\mathrm{dL}$ increase in glucose. Further, many studies have shown that lowering the average blood glucose level of hospitalized patients has a significant benefit on important clinical outcomes such as mortality and infection rates [24,25]. According to Newton and Young [26], the decrease in the LOS for patients with diabetes has resulted in a savings of more than $\$ 2$ million. This savings was calculated from the salaries of the Program Director, Program Administrative Office Assistant, as well as consultant fees for the Medical Director and the data management and product services provided by American Health ways. This added value yields a $467 \%$ return on investment [26].

\section{Conclusions}

This study has generated a new data about patient LOS with inpatient diabetic MI. The data gave a detailed and recent comparison between the quality of care in teaching and nonteaching hospitals for this population. This study has shown disparities in the LOS outcome and most significantly in the equity area in terms of differences in patient age, gender, ethnic group, comorbidities, income, and insurance possession. Hence, one notes an established association between hyperglycemia, LOS, and income in diabetic MI inpatients. However, future research should focus on more robust data and future ICD codes that would distinctively differentiate STEMI from NSTEMI for a more measurable and valid outcomes.

\section{Acknowledgement}

This grant is supported in part by National Institute of Health, National Center for Minority Health and Health Disparities, IS22 MD00241-21

\section{References}

1. Donna D. Ignatavicius, Workman ML (2009) Medical-Surgical nursing. Patientcentered collaborative care. (6thedn), Elsevier Sounders, St Loius, USA.

2. US Preventive Services Task Force (2002) Aspirin for the primary prevention of cardiovascular events: recommendation and rationale. Ann Intern Med 136: $157-160$

3. Yuan Z, Cooper GS, Einstadter D, Cebul RD, Rimm AA (2000) The association between hospital type and mortality and length of stay: a study of 16.9 million hospitalized Medicare beneficiaries. Med Care 38: 231-245.

4. Allison JJ, Kiefe Cl, Weissman NW, Person SD, Rousculp M, et al. (2000) Relationship of hospital teaching status with quality of care and mortality for Medicare patients with acute MI. JAMA 284: 1256-1262.

5. Polanczyk CA, Lane A, Coburn M, Philbin EF, William, G, et al. (2002) Hospital Outcomes in Major Teaching, Minor Teaching, and Nonteaching Hospitals in New York State. Am J Med 112: 255-261.

6. Dowell MA, Rozell B, Roth D, Delugach H, Chaloux P, et al. (2004) Economic and clinical disparities in hospitalized patients with type 2 diabetes. J Nurs Scholarsh 36: 66-72.

7. Cunningham WE, Tisnado DM, Lui HH, Nakazono TT, Carlisle DM (1990) The effect of hospital experience on mortality among patients hospitalized with acquired immunodeficiency syndrome in California. Am J Medicinet 107: 137143.

8. Ayanian JZ, Weissman JS, Chasan-Taber S, Epstein AM (1998) Quality of care for two common illnesses in teaching and nonteaching hospitals. Health Aff (Millwood) 17: 194-205

9. Romano PS, Geppert JJ, Davies S, Miller MR, Elixhauser A, et al. (2003) A national profile of patient safety in U.S. hospitals. Health Aff (Millwood) 22: 154 166.

10. Sloan FA, Conover CJ, Provenzale D (2000) Hospital credentialing and quality of care. Soc Sci Med 50: 77-88.
11. Cook CB, Naylor DB, Hentz JG, Miller WJ, Tsui C, et al. (2006) Disparities in diabetes-related hospitalizations: relationship of age, sex, and race/ethnicity with hospital discharges, lengths of stay, and direct inpatient charges. Ethn Dis 16: 126-131.

12. Okunji PO (2010) Outcomes of patients with diabetic myocardial infarction in non federal hospitals: Effects of hospital and patient characteristics. Udin ProQuest.

13. Donabedian A (1966) Evaluating the quality of medical care. Milbank Mem Fund Q 44: 166-206

14. Odum SM, Springer BD, Dennos AC, Fehring TK (2013) National Obesity Trends in Total Knee Arthroplasty. J Arthroplasty.

15. HCUP Clinical Classifications Software (CCS) for ICD-9-CM. Healthcare Cost and Utilization Project (HCUP) 2008. Agency for Healthcare Research and Quality, Rockville, MD.

16. Hogan P, Dall T, Nikolov P; American Diabetes Association (2003) Economic costs of diabetes in the US in 2002. Diabetes Care 26: 917-932.

17. Healthcare Reform Law (2010) Implementation Timeline for Small Business.

18. Steinberg BA, French WJ, Peterson ED, Frederick PD, Cannon CP, et al. (2006) Missed diagnosis of the diagnosis codes: comparison of International Classification of Diseases, 9th Revision coding and ST- versus non-STelevation myocardial infarction diagnosis in the National Registry of Myocardial Infarction. Crit Pathw Cardiol 5: 59-63.

19. Donnan PT, Leese GP, Morris AD (2000) Hospitalizations for people with type 1 and type 2 diabetes compared with the nondiabetic population of Tayside Scotland: a retrospective cohort study of resource use. Diabetes Care 23 1774-1779.

20. Umpierrez GE, Isaacs SD, Bazargan N, You X, Thaler LM, et al. (2002) Hyperglycemia: an independent marker of in-hospital mortality in patients with undiagnosed diabetes. J Clin Endocrinol Metab 87: 978-982.

21. Williams LS, Rotich J, Qi R, Fineberg N, Espay A, et al. (2002) Effects of admission hyperglycemia on mortality and costs in acute ischemic stroke. Neurology 59: 67-71.

22. Olveira-Fuster G, Olvera-Márquez P, Carral-Sanlaureano F, González-Romero $\mathrm{S}$, Aguilar-Diosdado M, et al. (2004) Excess hospitalizations, hospital days, and inpatient costs among people with diabetes in Andalusia, Spain. Diabetes Care 27: 1904-1909.

23. Estrada CA, Young JA, Nifong LW, Chitwood WR Jr (2003) Outcomes and perioperative hyperglycemia in patients with or without diabetes mellitus undergoing coronary artery bypass grafting. Ann Thorac Surg 75: 1392-1399.

24. van den Berghe G, Wouters P, Weekers F, Verwaest C, Bruyninckx F, et al. (2001) Intensive insulin therapy in critically ill patients. N Engl J Med 345: 1359 1367.

25. Furnary AP, Gao G, Grunkemeier GL, Wu Y, Zerr KJ, et al. (2003) Continuous insulin infusion reduces mortality in patients with diabetes undergoing coronary artery bypass grafting. J Thorac Cardiovasc Surg 125: 1007-1021.

26. Newton CA, Young S (2006) Financial implications of glycemic control: results of an inpatient diabetes management program. Endocr Pract 12: 43-48. 